\title{
Equilibrium Isotherms and Kinetic Studies of Removal of Methylene Blue Dye by Adsorption onto Miswak Leaves as a Natural Adsorbent
}

\author{
Taha M. Elmorsi ${ }^{1,2}$
}

${ }^{1}$ Chemistry Department, Faculty of Science, Jazan University, Jazan, KSA; ${ }^{2}$ Chemistry Department, Faculty of Science, Al-Azhar University, Cairo, Egypt.

Email: taha_elmorsi@yahoo.com

Received May $12^{\text {th }}, 2011$; revised June $24^{\text {th }}, 2011$; accepted July $29^{\text {th }}, 2011$.

\begin{abstract}
In this research miswak leaves, agriculture wastes, available in large quantity in Saudi Arabia, was used as low-cost adsorbent for removing methylene blue $(M B)$ dye. Equilibrium behavior of miswak leaves was investigated by performing batch adsorption experiments. The effects of $[M B] 0, p H$, contact time and adsorbent dose were evaluated. An alkaline $p H$ (10.6) was favorable to the adsorption of $M B$ dye. Adsorption isotherm models, Langmuir, Freundlich and Temkin were used to simulate the equilibrium data. Langmuir equation was found to have the highest value of R2 compared with other models. Furthermore, it was found that miswak leaves have a high adsorptive capacity towards $M B$ dye $(200 \mathrm{mg} / \mathrm{g})$ and show favorable adsorption of $M B$ dye with separation factor $\left(R_{L}<1\right)$. In addition, pseudo-firstorder, pseudo-second order and intra-particle diffusion were used to study the kinetics of MB adsorption onto miswak leaves. Adsorption process undergoes pseudo-second order kinetic as proved by the high value of $R 2$ and the low value of sum of squared error (SSE percentage). Results indicated that intra-particle diffusion is not the limiting step, and the adsorption process is spontaneous as indicated by the negative value of the $\Delta G$.
\end{abstract}

Keywords: Miswak Leaves, Salvadora Persica, Methylene Blue, Adsorption Isotherms, Adsorption Kinetics

\section{Introduction}

Presence of many pollutants in water and wastewater has increased recently due to high increase in various industrial activities. Using dyes in many industries [1] such as textile, paper, plastics, leather, food and cosmetic, represent a large group of chemicals that get mixed in wastewater among many aqueous pollutants. In recent years, there is a dramatic increase in the annual production of different synthetic dyes representing more than 10,000 dyes [2]. Many azo dyes and their intermediates have toxic effects on environment and human health due to their carcinogenicity and visibility [3]. It was reported that incomplete degradation of dyes by bacteria in the sediment resulted in production of some carcinogenic and harmful amines [4]. In addition, presences of color substances in the water body may decrease the light transmission which decreasing the photosynthesis activity, leading to decrease growth of bacteria and hence decreasing the biodegradation of impurities in water [5]. Methylene blue dye (MB), is basic dye has been extensively used in textiles and printing industry, and it has been found as non-biodegradable dye. Therefore, it is essential that wastewater contaminated with MB dye to be given some treatments before discharge.

Many treatment techniques have been applied to a broad range of water and wastewater contaminated with dyes including physical- or chemical-treatment processes [6]. These include chemical coagulation/flocculation $[7,8]$, ozonation, oxidation, photodegradation [9], ion exchange, irradiation, precipitation and adsorption. Several critical reviews on current treatment technologies were reported [10]. Many of these techniques are costly, required various tools and have limitations. It has been reported that the adsorption onto activated carbon, have proven to be the most efficient and reliable method for the removal many pollutants, including different dyes [7]. Although commercial activated carbon is very effective adsorbent, its high cost requires the search for alternatives and low-cost adsorbents [11]. Several low-cost adsorbents have been 
tested for removing dyes [12] including peat, pith, Orange peel, Indian Rosewood [11], cellulose based wastes, giant duckweed, banana pith and other agricultural by-products [12]. On the other hand, Salvadora persica (miswak or arak) is a common plant found widely in different areas in Jazan, Saudi Arabia in addition to other countries.

Miswak has been used by many Islamic communities as toothbrushes, and has been scientifically proven to be very useful in the prevention of tooth decay, even when used without any other tooth-cleaning methods $[13,14]$. However, roots of miswak only are used as a toothbrush and the rest of plant such as leaves possibly remain as an agriculture waste. To make further use of the plant, the present study is an attempt to use miswak tree leaves, as nonconventional low-cost adsorbent for removal of MB dye from aqueous solution. The capacity of adsorbent for adsorbate is obtained by adsorption isotherm model, which is the equilibrium relationships between adsorbent/adsorbate systems.

In this study, three models (Langmuir, Freundlich [15-19,] and Temkin [20,21] have been used to describe the sorption process of MB onto miswak leaves. Furthermore, kinetics of MB adsorption onto miswak leaves will be investigated using a pseudo-first order [15], a pseudo-second order [22,23] and an intraparticle diffusion [15-24]. Linear regression analysis method will be used to determine the most fitted model and finding its parameters [25].

\section{Experimental}

\subsection{Chemicals}

All chemicals used in this study were of analytical-grade and used without further purification. Methylene blue (MB) or basic blue-9 is a monovalent cationic dye with a molecular formula of C16H18N3ClS (Mo. Wt. 319.85 $\mathrm{g} / \mathrm{mol}$ ), used as the model adsorbate in the present study to evaluate the efficiency of leaves Salvadora persica (miswak) as a natural adsorbent. The chemical structure of $\mathrm{MB}$ is shown in Figure 1. $\mathrm{HCl}, \mathrm{NaOH}$ used to adjust the $\mathrm{pH}$ were purchased from $\mathrm{BDH}$.<smiles>CN(C)c1ccc2nc3ccc(=[N+](C)C)cc-3sc2c1</smiles>

Figure 1. Chemical structure of methylene blue dye (MB).

\subsection{Adsorbent}

Salvadora persica (miswak or arak) was used as a natural adsorbent. Salvadora persica plant is a member of the Salvadoraceae family. Leaves of miswak were collected from fields around El-Ardh area (Bathan) in Jazan, Saudi Arabia. Adsorbent was air dried and washed several times with distilled water, dried again then ground well and sieved.

\subsection{Preparation of Dye Solutions}

Methylene blue (MB) was used in this study as an environmental pollutant. Stock solutions $(1000 \mathrm{mg} / \mathrm{L})$ of MB dye were prepared by dissolving the required amount in distilled water. Batch experimental solutions were obtained by diluting the dye stock solutions in accurate different initial concentrations. Calibration curves were prepared by serial dilutions ( 1.0 to $10.0 \mathrm{mg} / \mathrm{L}$ ).

\subsection{Adsorption Studies}

In batch adsorption experiments, certain amounts of miswak were added into several $10 \mathrm{~mL}$ bottles, each containing $5.0 \mathrm{~mL}$ solution of $\mathrm{MB}$ dye with $[\mathrm{MB}]_{0}$ of 120 $\mathrm{mg} / \mathrm{L}$. Then the bottles were stirred at $800 \mathrm{rpm}$ for 80 min using a magnetic stirrer at room temperature. Miswak in the samples was separated by centrifugation and the concentrations of dye at any time $\left(C_{t}\right)$ were determined in the supernatant solutions. Adsorption isotherms were determined by introducing $0.005 \mathrm{~g}(1.0 \mathrm{~g} / \mathrm{L})$ miswak to respective $5.0 \mathrm{~mL}$ of different dye concentrations $(16-150 \mathrm{mg} / \mathrm{L})$ at room temperature.

\subsection{Effect of Adsorbent Mass}

To investigate the effect of adsorbent mass, different mass of miswak 0.005 to $0.015 \mathrm{~g}(1-3 \mathrm{~g} / \mathrm{L})$ was introduced to a number of glass tubes containing a specific volume of a fixed $[\mathrm{MB}]_{0}$ at the same $\mathrm{pH}$ and room temperature. Concentrations of MB were measured at equilibrium.

\subsection{Effects of Initial Dye Concentration $\left(C_{0}\right)$ and Contact Time}

To evaluate the effect of both contact time and adsorption kinetic, experiments were conducted at different periods using previously described system.

\subsection{Analytical Methods}

Standard solution of MB dye was used to obtain calibration curves. UV-vis spectrophotometer (APEL) was used for determining the concentrations of dye solutions. For each adsorption experiment, samples were withdrawn at interval times, and the adsorbate (miswak) was separated 
by the centrifuge. Then concentrations of residual dye solutions were measured by monitoring the absorbance changes at a wavelength of maximum absorbance $\left(\lambda_{\max }=\right.$ $665 \mathrm{~nm}$ ) for MB dye. The amount of dye sorbed at any time, $q_{t}$, was calculated from;

$$
q_{t}=\frac{V\left(C_{0}-C_{t}\right)}{W}
$$

At equilibrium, $q_{t}=q_{e}$ and $C_{t}=C_{e}$; therefore, the amount of sorbed dye, $q_{e}$, was calculated from

$$
q_{e}=\frac{V\left(C_{0}-C_{e}\right)}{W}
$$

where $C_{0}, C_{t}$ and $C_{e}$ are the initial concentration, concentration at any time and equilibrium concentrations of dye solution $(\mathrm{mg} / \mathrm{L})$, respectively, $V$ is the volume of the solution (L), and $W$ is the mass of adsorbent $(\mathrm{g})$ [26].

The dye removal percentage can be calculated as follows:

$$
\text { Removal } \%=\frac{\left(C_{0}-C_{t}\right)}{C_{0}} \times 100
$$

\subsection{Equilibrium Isotherm Modeling}

The experimental data at equilibrium between the amount of adsorbed dye $\left(q_{e}\right)$ on the adsorbent (miswak) and the concentration of dye in solution $\left(C_{e}\right)$ at a constant temperature and $\mathrm{pH}$ were used to describe the optimum isotherm model. The linear forms of Langmuir, Freundlich [15-19] and Temkin [20,21] equations (Table 1) were used to describe the equilibrium data. Applicability of these equations was compared by judging the correlation coefficients $\left(R^{2}\right)$ [25].

\subsubsection{Langmuir Isotherm}

The Langmuir isotherm model is used to predict the sorption of aqueous compounds onto a solid phase [15, 19]. This mechanistic model assumes that a monolayer of adsorbed material (in liquid, such as MB) is adsorbed over a uniform adsorbent surface (a flat surface of solid phase, such as miswak leaves) at a constant temperature and that the distribution of the compound between the two phases is controlled by equilibrium constant. Hence at equilibrium both rates of adsorption and desorption are equal. The Langmuir equation is derived as:

$$
q_{e}=\frac{q_{m} K_{L} C_{e}}{1+K_{L} C_{e}}
$$

where $q_{m}$ (the maximum capacity of adsorption, $\mathrm{mg} / \mathrm{g}$,) and $K_{L}$ (a constant related to the affinity of the binding sites, $\mathrm{L} / \mathrm{mg}$,) are the Langmuir isotherm constants. Both $q_{m}$ and $K_{L}$ will greatly impact the conclusions made about the experimental data and can be determined by a simple method of equation optimization by linear regression [25]. That is to transform the isotherm variables to a linear form and then to apply the linear regression analysis of known $C_{e}$ and $q_{e}$ values as described by Lineweaver-Burk (Langmuir-II).

\subsubsection{Freundlich Isotherm}

Freundlich isotherm model $[15,19]$ is assuming that the adsorption process takes place on a heterogeneous surface. The Freundlich exponential equation is given as:

$$
q_{e}=K_{F} C^{1 / n}
$$

where $K_{F}((\mathrm{~L} / \mathrm{mg})$ is an indicator of the adsorption capacity and $1 / n$ is the adsorption intensity and indicates both the relative distribution of energy and the heterogeneity of the adsorbent sites. The linear form is derived by taking the log of the terms as shown in Table 1 .

\subsubsection{Temkin Isotherm}

Temkin isotherm model (Equation (5)) was used also to test the adsorption potential of miswak leaves to MB dye. This model is taking into account the effects of indirect adsorbate/adsorbate interactions on the adsorption process. Furthermore, the model is assuming that the heat of adsorption $\left(\Delta \mathrm{H}_{\mathrm{ads}}\right)$ of all molecules in the layer decreased linearly by increase the coverage. The linear form of

\begin{tabular}{|c|c|c|c|c|c|}
\hline Isotherm & Nonlinear form & Linear form & & Plot & \\
\hline Langmuir-II & $q_{e}=\frac{K L C_{e}}{1+K L C_{e}}$ & $\frac{1}{q_{e}}=\left(\frac{1}{K_{L} q_{m}}\right) \frac{1}{C_{e}}+\left(\frac{1}{q_{m}}\right)$ & $\frac{1}{q_{e}}$ & VS. & $\frac{1}{C_{e}}$ \\
\hline Freundlich & $q_{e}=K_{F} C_{e}^{1 / n}$ & $\log q_{e}=\log K_{F}+\frac{1}{n} \log C_{e}$ & $\log q_{e}$ & VS. & $\log C_{e}$ \\
\hline Temkin & $q_{e}=\frac{R T}{b_{T}} \ln \left(K_{T} C_{e}\right)$ & $q_{e}=\frac{R T}{b_{T}} \ln K_{T}+\frac{R T}{b_{T}} \ln C_{e}$ & $q_{e}$ & VS. & $\ln C_{e}$ \\
\hline
\end{tabular}
Temkin is given as follows:

$$
q_{e}=\frac{R T}{b_{T}} \ln K_{T}+\frac{R T}{b_{T}} \ln C_{e}
$$

Table 1. Different isotherm models used in this study and their linear forms. 
where, $R$ is common gas constant $(0.008314 \mathrm{~kJ} / \mathrm{mol} \mathrm{K})$, $T$ is the absolute temperature $(\mathrm{K}), 1 / b_{T}$ is the Temkin constant related to the heat of sorption $(\mathrm{kJ} / \mathrm{mol})$ which indicates the adsorption potential (intensity) of the adsorbent and $K_{T}(\mathrm{~L} / \mathrm{g})$ is Temkin constant related to adsorption capacity. The liner plots of $q_{e}$ versus $\ln C_{e}$ enable to determine the constants $1 / b_{T}$ and $K_{T}$ from the slope and intercept respectively.

\section{Results and Discussion}

\subsection{Effects of Initial Dye Concentration $\left(C_{0}\right)$ and Contact Time}

A miswak leaves dosage of $0.005 \mathrm{~g}(1.0 \mathrm{~g} / \mathrm{L})$ was added to $0.005 \mathrm{~L}$ of different concentrations $(16-150 \mathrm{mg} / \mathrm{L})$ of MB dye solution. Experiments were conducted at a temperature of $303 \mathrm{~K}$ for $80 \mathrm{~min}$ to test the effect of initial concentration and contact time on the adsorption process. The results (Figure 2) indicated that the adsorption of MB dye onto miswak increases as $[\mathrm{MB}]_{0}$ increased. At the first $10 \mathrm{~min}$ of the adsorption process, as $[\mathrm{MB}]_{0}$ increased by 9.4 times (from 16 to $150 \mathrm{mg} / \mathrm{L}$ ), the adsorbed amount $\left(q_{t}\right)$ onto miswak leaves increased 6.5 times (from 6.2 to $40.0 \mathrm{mg} / \mathrm{g}$ ). Also, as the contact time increased to $30 \mathrm{~min}, \mathrm{q}_{\mathrm{t}}$ increased by about seven times (from 9.01 to $62.13 \mathrm{mg} / \mathrm{g}$ ). Therefore, the adsorption of MB dye was very rapid during the first $10 \mathrm{~min}$, and increased gradually during the second 20 min until reached equilibrium at $30 \mathrm{~min}$. The results showed that the uptake of MB dye by miswak leaves depends on $[\mathrm{MB}]_{0}$ and contact time. This is because $[\mathrm{MB}]_{0}$ act as the driving force that increases the mass transfer of MB dye from aqueous solution onto the surface of miswak leaves. During the adsorption process, solutions with different initial concentrations possibly will reach equilibrium at different times. This may be due to the time required for the dye molecules to encounter the boundary layer effect, then diffuse to the surface of the adsorbent and finally diffuse to the porous structure of the adsorbent [27]. Therefore, solutions with low initial concentration (16 $\mathrm{mg} / \mathrm{L}$ ) reached equilibrium first at about $30 \mathrm{~min}$, while solutions with high initial concentration of $150 \mathrm{mg} / \mathrm{L}$ takes longer time and reached equilibrium at $60 \mathrm{~min}$. To ensure complete equilibrium of the data, adsorption samples were collected at $80 \mathrm{~min}$. It was noted that as $[\mathrm{MB}]_{0}$ dye increased from 16 to $150 \mathrm{mg} / \mathrm{L}$, the removal \% at equilibrium decreased by $25 \%$ (from 55.78 to $41.79 \%$ ). This may be because the constant number of available sites in miswak leaves is easily saturated by the increase of $[\mathrm{MB}]_{0}$, which would lead to a decrease in the removal percentage of MB dye. Other researchers reported similar trend [28,29]. Furthermore, Figure 2 indicated that the increase in $[\mathrm{MB}]_{0}$ from 120 to $150 \mathrm{mg} / \mathrm{L}$ led to slight improve in the adsorption capacity of MB onto miswak leaves. Consequently, $120 \mathrm{mg} / \mathrm{L}$ of $\mathrm{MB}$ was chosen as an optimum $[\mathrm{MB}]_{0}$ for further experiments.

\subsection{Effect of Solution pH on Dye Removal}

Experiments were conducted at $120 \mathrm{mg} / \mathrm{L}[\mathrm{MB}]_{0}, 1.0 \mathrm{~g} / \mathrm{L}$ miswak leaves dose, and 80 min contact time at $303 \mathrm{~K}$, to study the effect of solution $\mathrm{pH}$ on the equilibrium adsorption capacity $\left(q_{e}\right)$ of MB dye onto miswak leaves as shown in Figure 3. It is indicated that $q_{e}$ of MB dye reaching a maximum in a basic medium and decreased by decreasing the $\mathrm{pH}$ values in the acidic medium. The $\mathrm{q}_{\mathrm{e}}$ of MB dye in a basic medium (at the $\mathrm{pH}$ range of 10.6 to 12.0) reached $60.9 \mathrm{mg} / \mathrm{g}$ and become about 13.54 at $\mathrm{pH}$ 2.8. Therefore, further adsorption experiments were performed at $\mathrm{pH} 10.6$ as an optimum $\mathrm{pH}$ value. The variations in the $\mathrm{pH}$ values from acidic to alkaline medium would affect the adsorption rate because both the degree of ionization of dye molecules and the surface properties of the adsorbent (miswak leaves) would vary. It is previously reported that the adsorption process increased by increasing the electrostatic attraction [2]. Thus anionic dyes (dye ${ }^{-}$) are favorably adsorbed by the adsorbent at

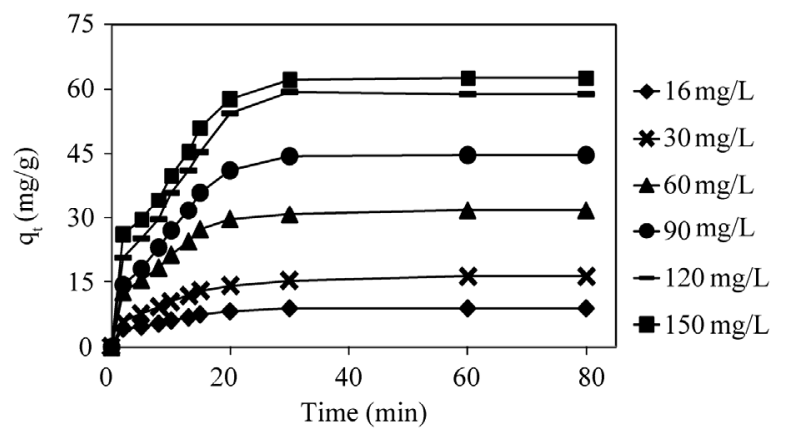

Figure 2. Effect of initial concentration and contact time on the adsorption of $\mathrm{MB}$ dye $\left(T=303 \mathrm{~K}, \mathrm{pH}_{\mathrm{i}}=10.6\right.$ miswak dosage $=1.0 \mathrm{~g} / \mathrm{L},[\mathrm{MB}]_{\mathrm{i}}=16-150 \mathrm{mg} / \mathrm{L}, V=0.005 \mathrm{~L}$ ).

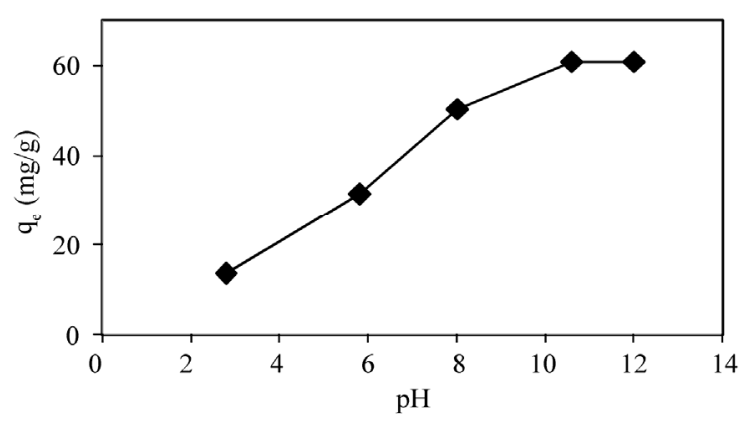

Figure 3. Effect of $\mathrm{pH}$ on the adsorption process $(T=303 \mathrm{~K}$, miswak dosage $=1.0 \mathrm{~g} / \mathrm{L},[\mathrm{MB}]_{\mathrm{i}}=120 \mathrm{mg} / \mathrm{L}, V=0.005 \mathrm{~L}$ ). 
lower $\mathrm{pH}$ values due to the presence of $\mathrm{H}^{+}$ions, while adsorption of cationic dyes $\left(\right.$ dye $\left.^{+}\right)$are favorably adsorbed at higher $\mathrm{pH}$ values, which led to increase the presence of $\mathrm{OH}^{-}$ions as a result of an increase the electrostatic attraction in each case [2]. Therefore, performing the adsorption in the basic medium, at $\mathrm{pH} 10.6$, would increase the negative charge on the adsorbent surface causing an increase in the electrostatic attraction between cationic dye molecules $\left(\mathrm{MB} d y \mathrm{e}^{-}\right)$and the surface of miswak leaves, hence increasing the adsorption rate of MB dye. On the other hand, the presence of high concentration of $\mathrm{H}^{+}$ions in the acidic medium at $\mathrm{pH} 2.8$ would make them compete effectively with cationic dye molecules (MB dye $\mathrm{e}^{-}$) causing a decrease in the amount of dye adsorbed. These results can be further proven by opposite behaviour shown for the adsorption of anionic dyes such as methyl orange (MO) onto Lapindo volcanic mud (LVM) [30]. It was found that the highest adsorption capacity was obtained at $\mathrm{pH} 3$. In addition, a similar trend was shown by the adsorption of some metal cations onto different adsorbents [31,32].

\subsection{Effect of Adsorbed Amount}

At constant $[\mathrm{MB}]_{0}(120 \mathrm{mg} / \mathrm{L})$, different amounts of miswak $(0.5$ to $3.0 \mathrm{~g} / \mathrm{L})$ were added to dye solutions $(0.005 \mathrm{~L})$ to study the effect of miswak leaves amount on MB dye adsorption. Results in Figure 4 shows that the adsorption capacity of MB dye in the first stage increased rapidly with the increase in the adsorbent dose then increased slowly with the further increase in the adsorbent dose. It can be seen that at $1.0 \mathrm{~g} / \mathrm{L}$ of the adsorbent dose, the adsorption capacity of the dye reached the most at $60.90 \mathrm{mg} / \mathrm{g}$. Then an increase in the dose of miswak leaves from 1.0 to $3.0 \mathrm{~g} / \mathrm{L}$ resulted only in about $0.7 \mathrm{mg} / \mathrm{g}$ more to reach $61.8 \mathrm{mg} / \mathrm{g}$. Thus $1.0 \mathrm{~g} / \mathrm{L}$ of miswak leaves was chosen as the optimum dose and used in the further experiments. The increase in adsorption capacity of MB dye with the increase in the amount of miswak leaves up to $1.0 \mathrm{~g}$ can be assigned to the increase in both the surface area and the adsorption sites to MB dye molecules [23,33]. The adsorption of methylene blue and indigo carmine dye onto different adsorbents such as grass waste, rice husk ash, and bamboo-based activated carbon respectively $[23,29,33]$ was reported with a similar trend.

\subsection{Isotherms for the Sorption Process}

\subsubsection{Langmuir isotherms}

Linear fit of Langmuir-II for the adsorption of MB onto miswak leaves at $30^{\circ} \mathrm{C}$ is shown in Figure 5. The value of $q_{m}, K_{L}$ and $R^{2}$ are presented in Table 2. The results indicated that linear form of Langmuir-II model shows

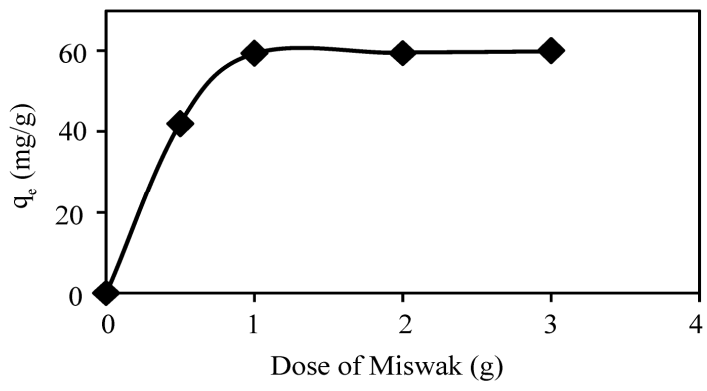

Figure 4. Effect of adsorbent dose on the adsorption process $\left(T=303 \mathrm{~K}, \mathrm{pH}_{\mathrm{i}}=10.6,[\mathrm{MB}]_{\mathrm{i}}=120 \mathrm{mg} / \mathrm{L}, V=0.005 \mathrm{~L}\right)$.

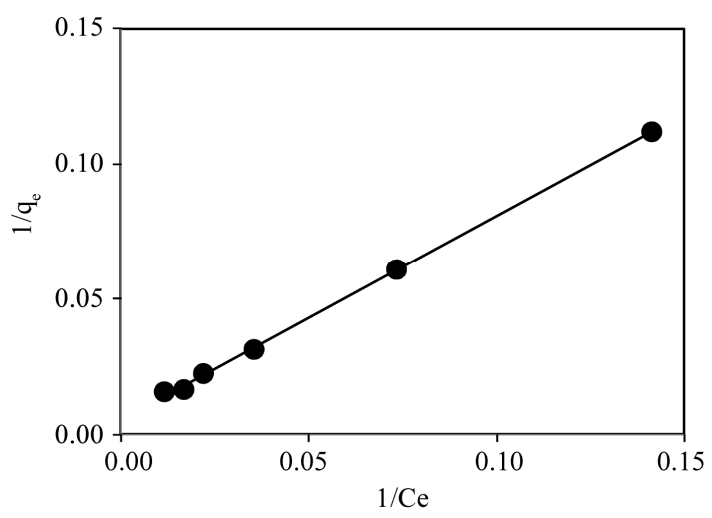

Figure 5. Langmuir isotherm $(T=303 \mathrm{~K}$, miswak dosage $=$ $\left.1.0 \mathrm{~g} / \mathrm{L},[\mathrm{MB}]_{\mathrm{i}}=16-150 \mathrm{mg} / \mathrm{L}, \mathrm{pH}_{\mathrm{i}}=10.6, \mathrm{~V}=0.005 \mathrm{~L}\right)$.

Table 2. Langmuir, Freundlich and Temkin constants for the adsorption process.

\begin{tabular}{cccccccccc}
\hline \multicolumn{3}{c}{ Langmuir constants } & \multicolumn{3}{c}{ Freundlich constants } & \multicolumn{3}{c}{ Temkin constants } \\
\hline$q_{m}$ & $K_{L}$ & $R^{2}$ & $K_{F}$ & $\mathrm{n}$ & $R^{2}$ & $b_{T}$ & $K_{T}$ & $R^{2}$ \\
$(\mathrm{mg} / \mathrm{g})$ & $(\mathrm{L} / \mathrm{mg})$ & & $(\mathrm{L} / \mathrm{mg})$ & $n$ & & $(\mathrm{~L} / \mathrm{mg})$ & $R^{2}$ \\
200 & 0.0067 & 0.999 & 1.750 & 1.176 & 0.993 & 0.101 & 0.161 & 0.950 \\
\hline
\end{tabular}

the minimal deviation from the fitted equation as indicated by the high value of $R^{2}$ as 0.999 . It was proposed that when the value of $R^{2}$ is greater than 0.89 , the adsorption data would follow the Langmuir model [2]. Furthermore, the value of $q_{m}$ which is the measure of the maximum adsorption capacity of miswak leaves for MB dye was calculated as $200 \mathrm{mg} / \mathrm{g}$ (Table2). Representing the experimental data by Langmuir isotherm indicates both the homogeneous nature of miswak leaves surface and the formation of monolayer coverage of MB dye molecule at its outer surface [23]. Other researchers reported similar observations for the adsorption of different dyes onto activated carbon prepared from various sources. Adsorption of acid orange 10 dye [34], direct dyes [35] and Congo red dye [36] onto activated carbon prepared from bagasse, sawdust and coir pith respectively. 


\subsubsection{Separation Factor}

Separation factor $\left(R_{L}\right)$, is a dimensionless constant [21, $23]$, and it is a good characteristic of the Langmuir isotherm. $R_{L}$, can be expressed in the following equation:

$$
R_{L}=\frac{1}{1+K_{L} C_{0}}
$$

where $C_{0}(\mathrm{mg} / \mathrm{L})$ is the highest $[\mathrm{MB}]_{0}$ and $K_{L}(\mathrm{~L} / \mathrm{mg})$ is Langmuir constant. The value of $R_{L}$ indicates the shape of the isotherm to be either linear $\left(R_{L}=1\right)$, unfavourable $\left(R_{L}>1\right)$, favourable $\left(0<R_{L}<1\right)$, or irreversible $\left(R_{L}=0\right)$. Thus the $R_{L}$ values between 0 and 1 indicate favourable adsorption. Plot of $R_{L}$ versus $C_{0}$ of $\mathrm{MB}$ at $30^{\circ} \mathrm{C}$ is shown in Figure 6. The $R_{L}$ values were in the range of 0.500 to 0.904 , which is less than unity, indicating that the adsorption of MB onto miswak leaves is a favourable process, and the data fits Langmuir isotherm model. Accordingly, miswak leaves is a good adsorbent for MB dye.

\subsubsection{Freundlich Isotherm}

Equilibrium adsorption data of MB dye onto miswak leaves was tested with Freundlich isotherm model. The linear plot of Freundlich isotherm at $303 \mathrm{~K}$ (Figure 7) is employed to determine the intercept value of $K_{F}$ and the slope $1 / n$ along with $R^{2}$ (Table 2). Although, the value of $R^{2}(0.993)$ of Freundlich is slightly lower than the value of $R^{2}(0.999)$ of Langmuir-II isotherm. The value of $1 / n$ (indicative of favorability) is 0.85 , which is close to the unity and indicates the favorability of the adsorption process [5]. Therefore, Freundlich model is still a good model to describe the adsorption data.

\subsubsection{Temkin Isotherms}

In addition, Temkin adsorption isotherm was chosen to fit with the equilibrium adsorption data. The linear plot of the Temkin isotherm at $303 \mathrm{~K}$ is illustrated in Figure 8. The parameters, $K_{T}$ and $b_{T}$ of the Temkin equation have been calculated for MB dye (Table2). Due to the low value of both adsorption capacity, $K_{T},(0.161 \mathrm{~L} / \mathrm{g})$ and the value of $R^{2}(0.95)$, the data of equilibrium isotherms of MB onto miswak is poorly described by the Temkin model. On the other hand, comparison of maximum monolayer adsorption capacity $\left(q_{m}\right)$ of $\mathrm{MB}$ onto various adsorbents obtained in the literature is presented in Table 3 in order to compare the efficiency of miswak leaves. It can be seen that miswak leaves are very effective adsorbent for cationic dyes such as MB with a relatively large adsorption capacity of $200 \mathrm{mg} / \mathrm{g}$ when compared with some other adsorbents.

\subsection{Adsorption Kinetics}

In order to study the adsorption of MB onto miswak leaves and to interpret the results, experimental data obtained were fitted into different kinetic models such as the pseudo-first-order [15], the pseudo-second order [22, $23]$ and an intraparticle diffusion [15,24].

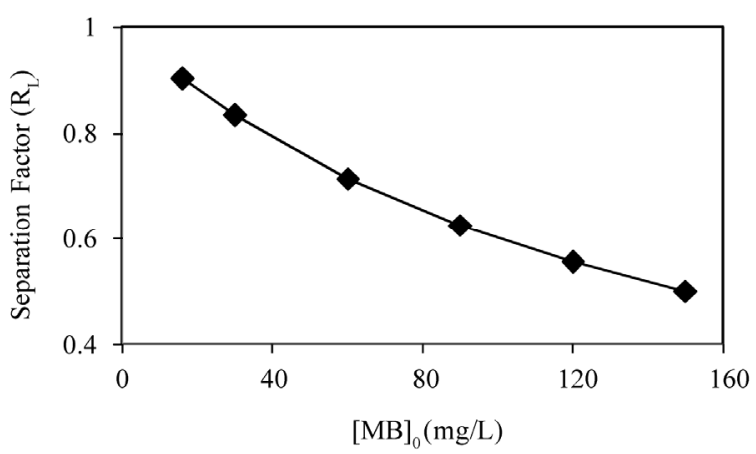

Figure 6. Plot of separation factor versus $[\mathrm{MB}]_{\mathrm{i}}(T=303 \mathrm{~K}$, miswak dosage $=1.0 \mathrm{~g} / \mathrm{L},[\mathrm{MB}]_{\mathrm{i}}=16-150 \mathrm{mg} / \mathrm{L}, \mathrm{pH}_{\mathrm{i}}=10.6$, $V=0.005$ L).

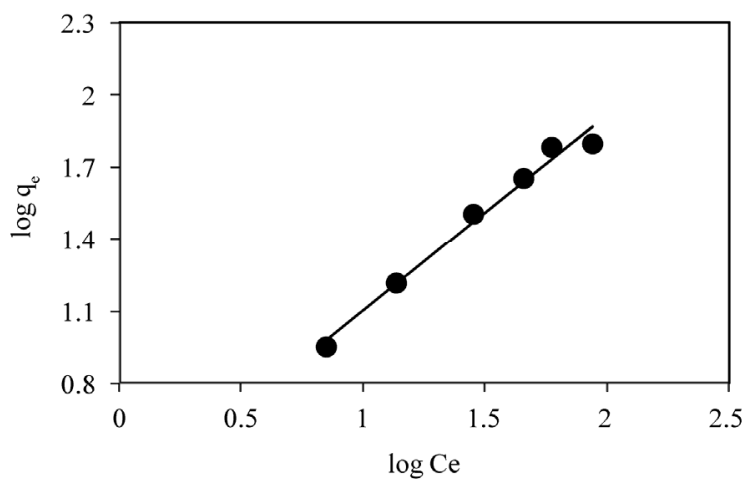

Figure 7. Freundlich isotherm $(T=303 \mathrm{~K}$, miswak dosage $=$ $\left.1.0 \mathrm{~g} / \mathrm{L},[\mathrm{MB}]_{\mathrm{i}}=16-150 \mathrm{mg} / \mathrm{L}, \mathrm{pH}_{\mathrm{i}}=10.6, V=0.005 \mathrm{~L}\right)$.

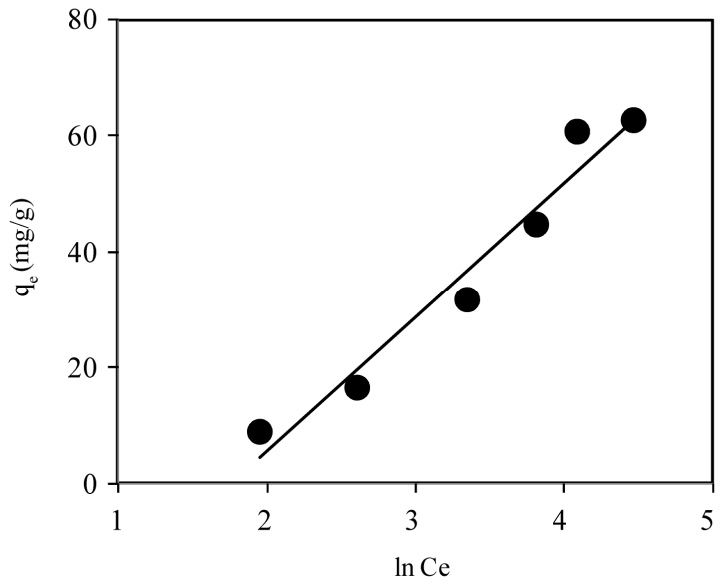

Figure 8. Temkin isotherm $(T=303 \mathrm{~K}$, miswak dosage $=1.0$ $\mathrm{g} / \mathrm{L},[\mathrm{MB}]_{\mathrm{i}}=16-150 \mathrm{mg} / \mathrm{L}, \mathrm{pH}_{\mathrm{i}}=10.6, V=0.005 \mathrm{~L}$ ). 
Table 3. Comparison of the maximum monolayer adsorption of MB onto various adsorbents.

\begin{tabular}{lcc}
\hline \multicolumn{1}{c}{ Adsorbents } & $\boldsymbol{q}_{\boldsymbol{m}}(\mathbf{m g} / \mathbf{g})$ & References \\
\hline Miswak leaves & 200 & This study \\
Natural Jordanian tripoli & 16.6 & {$[1]$} \\
Banana peel & 20.8 & {$[15]$} \\
Orange peel & 18.6 & {$[15]$} \\
Activated carbon prepared & 243.90 & {$[37]$} \\
from oil palm shell & 200 & {$[38]$} \\
Activated furniture $\left(850^{\circ} \mathrm{C}\right)$ & 130 & {$[38]$} \\
Activated tyres $\left(850^{\circ} \mathrm{C}\right)$ & 120 & {$[38]$} \\
Activated sewage char $\left(800^{\circ} \mathrm{C}\right)$ & 80 & {$[38]$} \\
Pyrolysed furniture & 454.2 & {$[23]$} \\
bamboo-based activated carbon & 294.26 & {$[39]$} \\
Pineapple leaf powder $(\mathrm{PLP})$ & & \\
\hline
\end{tabular}

\subsubsection{Pseudo First-Order Equation}

The rate constant of adsorption is determined from the pseudo first-order equation given by Langergren and Svenska (1898) [15], which expressed as follows:

$$
\log \left(q_{e}-q_{t}\right)=\log q_{e}-\left(\frac{k_{1}}{2.303}\right) t
$$

where $q_{e}$ and $q_{t}$ are the amounts of the MB adsorbed $(\mathrm{mg} / \mathrm{g})$ at equilibrium and at time $t(\mathrm{~min})$, respectively, and $k_{1}$ is the rate constant adsorption $\left(\mathrm{min}^{-1}\right)$.

Values of $k_{1}$ and $q_{e}$ were calculated from the slope and the intercept of the plots of $\log \left(q_{e}-q_{t}\right)$ versus $t$ respectively at different concentrations (Figure 9). The results in Table 4 show that the values of $R^{2}$ were low and the experimental $q_{e}$ values do not agree well with the calculated values. This shows that the adsorption of the MB onto miswak is not first-order kinetics.

\subsubsection{Pseudo-Second-Order Rate Equation}

Equation of pseudo second-order based on equilibrium adsorption [22-23] can be expressed as:

$$
\frac{\mathrm{d}_{q}}{\mathrm{~d}_{t}}=k_{2}\left(q_{e}-q_{t}\right)^{2}
$$

or

$$
\frac{t}{q_{t}}=\frac{1}{\left(k_{2 \times q_{e}^{2}}\right)}+\left(\frac{1}{q_{e}}\right) x t
$$

where, $k_{2}(\mathrm{~g} / \mathrm{mg} \cdot \mathrm{min})$ is the adsorption rate constant of pseudo second-order adsorption rate. The value of $q_{e}$ and $k_{2}$ can be from the slope and intercept of the plot of $\frac{t}{q_{t}}$ versus $t$ respectively. The results in Figure 10 show linear plots for all different initial concentrations

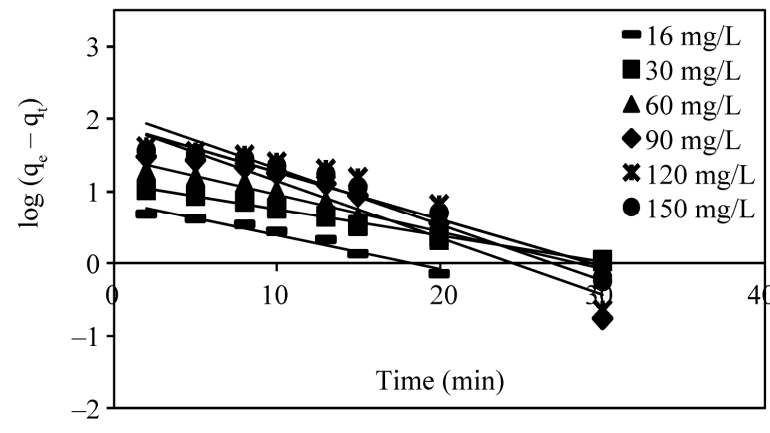

Figure 9. Pseudo-first-order kinetics for the adsorption process $\left(T=303 \mathrm{~K}\right.$, miswak dosage $=1.0 \mathrm{~g} / \mathrm{L},[\mathrm{MB}]_{\mathrm{i}}=16$ $-150 \mathrm{mg} / \mathrm{L}, \mathrm{pH}_{\mathrm{i}}=10.6, V=0.005 \mathrm{~L}$ ).

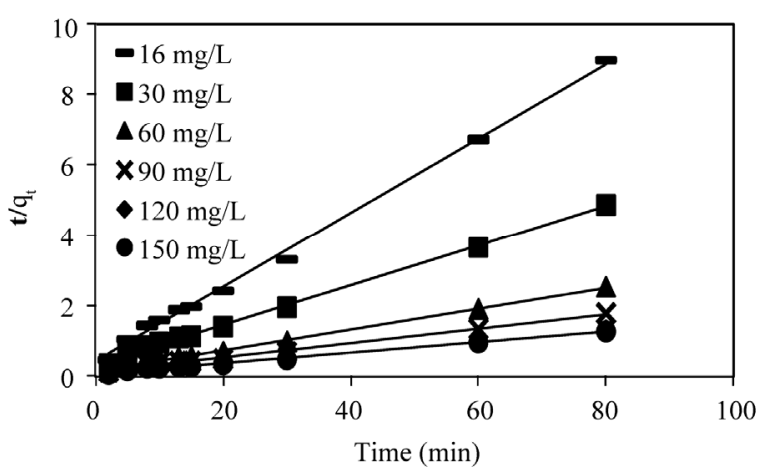

Figure 10. Pseudo-second order kinetics for the adsorption process $\left(T=303 \mathrm{~K}\right.$, miswak dosage $=1.0 \mathrm{~g} / \mathrm{L},[\mathrm{MB}]_{\mathrm{i}}=16$ $-150 \mathrm{mg} / \mathrm{L}, \mathrm{pH}_{\mathrm{i}}=10.6, \mathrm{~V}=0.005 \mathrm{~L}$ ).

studied with very high values of $R^{2}$ (Table 4) in addition to the good agreement between experimental and calculated values of $q_{e}$. Therefore, the adsorption of MB onto miswak is greatly represented by the pseudo second-order kinetics. Moreover, adsorption process of MB onto different natural adsorbents such as a pineapple leaf powder (PLP) undergoes second-order kinetics [40].

\subsubsection{Intraparticle Diffusion Study}

In order to investigate the mechanism of the MB adsorption onto miswak, intra-particle diffusion based mechanism was studied. It is proposed that the uptake of the adsorbate (MB dye) by the adsorbent (miswak leaves) varies almost proportionately with the square root of the contact time $\left(t^{1 / 2}\right)$. Weber and Morris [15,24] proposed the most-widely applied intra-particle diffusion equation for sorption system as:

$$
q_{t}=k_{i d} t^{1 / 2}
$$

where, $q_{t}$ is the amount of MB dye adsorbed per unit mass of adsorbent $(\mathrm{mg} / \mathrm{g})$ at a time $t$ and $k_{i d}$ the intra-particle diffusion rate constant $\left(\mathrm{mg} / \mathrm{g} \cdot \mathrm{min}^{-1 / 2}\right)$. The 
Table 4. Adsorption kinetic parameters for the adsorption process (miswak dosage $=1.0 \mathrm{~g} / \mathrm{L},[\mathrm{MB}]=16-150 \mathrm{mg} / \mathrm{L}, T=303$ $\mathrm{K}$, pH 10.6 and $V=0.005 \mathrm{~L})$.

\begin{tabular}{cccccccccc}
\hline \multicolumn{4}{c}{ First-order kinetic model } & \multicolumn{5}{c}{ Second-order kinetic model } \\
\hline$[\mathrm{MB}]_{0}$ & $q_{e}$, exp & $q_{e}$, cal & $k_{1}$ & $R^{2}$ & SSE & $q_{e}$, cal & $k_{2}$ & $R^{2}$ & SSE \\
\hline 16 & 8.93 & 7.18 & -0.1059 & 0.956 & 1.87 & 9.524 & 0.025 & 0.997 & 0.54 \\
30 & 16.40 & 13.18 & -0.0852 & 0.993 & 3.22 & 17.86 & 0.0096 & 0.998 & 1.30 \\
60 & 31.68 & 28.97 & -0.1175 & 0.977 & 18.50 & 34.48 & 0.0062 & 0.996 & 2.51 \\
90 & 44.66 & 86.90 & -0.1819 & 0.912 & 31.48 & 50.00 & 0.0031 & 0.996 & 4.77 \\
120 & 60.90 & 62.23 & -0.1128 & 0.901 & 47.71 & 66.67 & 0.0023 & 0.991 & 5.16 \\
150 & 62.69 & 84.14 & -0.1497 & 0.937 & 49.50 & 71.43 & 0.0025 & 0.994 & 7.82 \\
\hline
\end{tabular}

Units used for the above terms are as follow: $[M B]_{0}=(m g / L), q e=m g / g, k_{1}=m^{-1}, S S E=\%, k_{2}=g / m g \cdot m^{-1}$.

rate parameter $k_{i d}$ of stage $i$ is obtained from the slope of the straight line of $q_{t}$ versus $t^{1 / 2}$.

If the intra-particle diffusion is the mechanism of the adsorption process, then the plot of $q_{t}$ versus $t^{1 / 2}$ will be linear and if the plot passes through the origin, then the rate limiting process is only due to the intra-particle diffusion [41]. Otherwise, some other mechanism along with the intra-particle diffusion is also involved [2]. Figure 11 presented the intra-particle diffusion model. The results indicated that the plot of $q_{t}$ versus $t^{1 / 2}$ were not linear over the whole time range. Furthermore, it may be seen that the intra-particle diffusion of MB dye occurred in 2 stages. The first straight portion is attributed to the macropore diffusion (phase I) and the second linear portion is attributed to micro-pore diffusion (phase II) [41]. The intra-particle diffusion constants for these 2 stages $\left(k_{1 d}\right.$ and $\left.k_{2 d}\right)$ are given in Table 5. Results indicated that the adsorption of MB dye onto miswak involved more than one process, and the intra-particle transport is not the rate-limiting step. Such finding is similar to that made in previous works on adsorption [2]. In addition, the rate constants of the intra-particular diffusion on miswak were slow and increased by the increase in $[\mathrm{MB}]_{0}$, hence $\mathrm{MB}$ dye as a big molecule, diffused slowly among the particles during the adsorption process. Similarly, Jadhav, D. N. et al. [41], reported slow rate of sorption in case of big molecules such as acidic, basic and disperse dyes on sawdust, polymerized sawdust and sawdust carbon respectively.

On the other hand, the sorption rate was generally fast and the intra-particle diffusion was the rate-limiting step in case of sorption of metal ions [42] and sorption of different dyes onto banana and orange peels [15].

\subsection{Validity of Kinetic Models}

The applicability of both pseudo-first order and pseudosecond order models for the adsorption of $\mathrm{MB}$ onto miswak were verified at different $[\mathrm{MB}]_{0}$ using the sum of

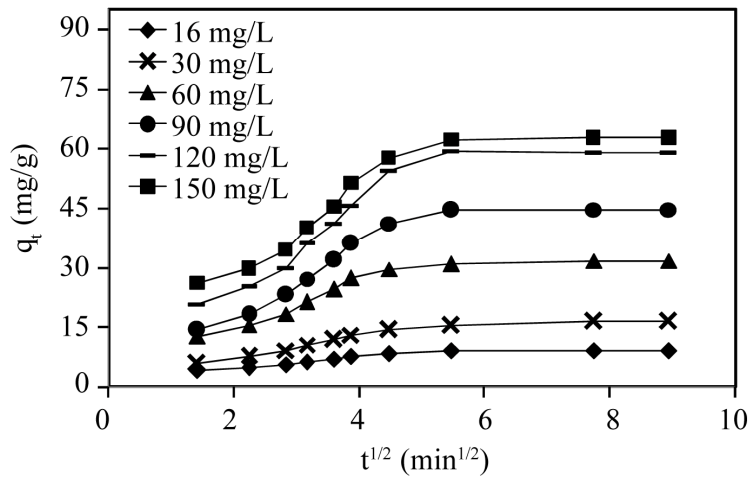

Figure 11. Intra-particle diffusion plot for the adsorption process (miswak dosage $=1.0 \mathrm{~g} / \mathrm{L},[\mathrm{MB}]=16-150 \mathrm{mg} / \mathrm{L}, \mathrm{T}$ $=303 \mathrm{~K}$, pH 10.6 and $V=0.005 \mathrm{~L}$ ).

Table 5. Weber-Morris parameters (miswak dosage $=1.0$ $\mathrm{g} / \mathrm{L},[\mathrm{MB}]=16-150 \mathrm{mg} / \mathrm{L}, T=303 \mathrm{~K}, \mathrm{pH} 10.6$ and $V=$ 0.005 L).

\begin{tabular}{ccccc}
\hline $\begin{array}{c}{[\mathbf{M B}]_{0},} \\
(\mathbf{m g} / \mathbf{L})\end{array}$ & $\begin{array}{c}K_{1 d} \\
\left(\mathbf{m g} / \mathbf{g} \cdot \mathbf{m i n}^{-1 / 2}\right)\end{array}$ & $R^{2}$ & $\begin{array}{c}K_{2 d} \\
\left(\mathbf{m g} / \mathbf{g} \cdot \mathbf{m i n}^{-1 / 2}\right)\end{array}$ & $R^{2}$ \\
\hline 16 & 1.413 & 0.971 & -0.027 & 0.884 \\
30 & 2.872 & 0.989 & 0.327 & 0.884 \\
60 & 5.944 & 0.973 & 0.276 & 0.884 \\
90 & 9.208 & 0.972 & 0.051 & 0.884 \\
120 & 11.200 & 0.958 & -0.138 & 0.884 \\
150 & 10.880 & 0.952 & 0.172 & 0.884 \\
\hline
\end{tabular}

squared error (SSE, percentage ) equation [23] given by:

$$
S S E=\frac{\sqrt{\left(q_{e, \exp }-q_{e, c a l}\right)^{2}}}{N}
$$

where, $N$ is the number of data points used in the linear plot of each model. The validity of these models was compared by judging the low value of $S S E, \%$ which indicates the better fit. The values of ( $S S E, \%)$ obtained for the two models listed in Table 3. It is indicated that 
the pseudo-second-order kinetic model yielded the lowest $S S E, \%$ values ( 0.535 to 7.819 ). Whereas, the firstorder model led to very high values of $S S E, \% \quad(1.87$ to 49.50). This agrees with the previous values of both $R^{2}$ and $q_{e, c a l}$ obtained earlier for the pseudo-second order (Table 3) to further prove the suitability of the pseudosecond-order kinetic to describe the adsorption process of MB onto miswak leaves. Also, a similar trend was reported for the adsorption of MB onto bamboo-based activated carbon [23].

\subsection{Standard Free Energy Change $\left(\Delta G^{\circ}\right)$}

Standard free energy $\left(\Delta G^{\circ}\right)$ can be calculated from the following equations [2];

$$
\begin{gathered}
\Delta G=-R T \ln K_{C} \\
K_{C}=\frac{q_{e}}{C_{e}}
\end{gathered}
$$

where, $T$ is the temperature $(\mathrm{K}), R$ is gas constant $(\mathrm{kJ} / \mathrm{mol} \cdot \mathrm{K}), K_{C}(\mathrm{~L} / \mathrm{g})$ is the standard thermodynamic equilibrium constant, $q_{e}$ is the amount of adsorbed $\mathrm{MB}$ dye per unit mass of miswak leaves at equilibrium $(\mathrm{mg} / \mathrm{g})$ and $C_{e}$ is the equilibrium aqueous concentration of MB. The Gibbs free energy change $\left(\Delta G^{\circ}\right)$ is negative indicating that the adsorption process of MB onto miswak is spontaneous.

\section{Conclusions}

The adsorption of MB dye onto miswak leaves was studied. Among the three different isotherm models, the equilibrium data was best fitted with the Langmuir-II equation. The equilibrium capacities based on the Langmuir analysis was $200 \mathrm{mg} / \mathrm{g}$ which is comparable with different adsorbents used for the adsorption of MB dye. Also, the equilibrium data can be modeled by Freundlich isotherm model. The adsorption of MB was favored by miswak leaves with value of RL less than unity. Furthermore, the adsorption process is spontaneous follows pseudo-second order kinetics and the mechanism involved more than one process. The present work revealed that the miswak leaves are a promising material for the removal of MB dye from aqueous solutions.

\section{Acknowledgements}

The Author is grateful to Dr. Zarrag I. Al-Fif (Vice Dean) and Dr. Yahya S. Masrahi, Biology Department, Faculty of Science, Jazan University, Jazan, KSA for their help and support.

\section{REFERENCES}

[1] Y. Bulut, N. Gozubenli and H. Aydın, "Equilibrium and
Kinetics Studies for Adsorption of Direct Blue 71 from Aqueous Solution by Wheat Shells," Journal of Hazardous Materials, Vol. 144, No. 1-2, 2007, pp. 300-306. doi:10.1016/i.jhazmat.2006.10.027

[2] A. S. ALzaydien, "Adsorption of Methylene Blue from Aqueous Solution onto a Low-Cost Natural Jordanian Tripoli," American Journal of Applied Sciences, Vol. 5, No. 1, 2009, pp. 197-208.

[3] R. Gong, M. Li, C. Yang, Y. Sun and J. Chen, "Removal of Cationic Dyes from Aqueous Solution by Adsorption on Peanut Hull," Journal of Hazardous Materials, Vol. 121, No. 1-3, 2005, pp. 247-250.

doi:10.1016/j.jhazmat.2005.01.029

[4] P. C. Vandevivere, R. Bianchi and W. Verstraete, "Treatment and Reuse of Wastewater from the Textile Wet-pro-Cessing Industry: Review of Emerging Technologies," Journal of Chemical Technology \& Biotechnology, Vol. 72, No. 4, 1998, pp. 289-302.

[5] T. Santhi, S. Manonmani, T. Smitha1, D. Sugirtha1 and K. Mahalakshmi, "Uptake of Cationic Dyes from Aqueous Solution by Bioadsorption onto Granular Cucumis Sativa," Journal of Applied Sciences in Environmental Sanitation, Vol. 4, No. 1, 2009, pp. 29-35.

[6] G. Crini, "Kinetic and Equilibrium Studies on the Removal of Cationic Dyes from Aqueous Solution by Adsorption onto a Cyclodextrin Polymer," Dyes and Pigments, Vol. 77, No. 2, 2008, pp. 415-426. doi:10.1016/j.dyepig.2007.07.001

[7] Z. Aksu, "Application of Biosorption for the Removal of Organic Pollutants: A Review," Process Biochemistry, Vol. 40, No. 3-4, 2005, pp. 997-1026. doi:10.1016/j.procbio.2004.04.008

[8] M. E. Mohammad and S. Muttucumaru, "Review of Pollutants Removed by Electrocoagulation and Electrocoagulation/Flotation Processes," Journal of Environmental Management, Vol. 90, No. 5, 2009, pp. 1663-1679. doi:10.1016/j.jenvman.2008.12.011

[9] T. M. Elmorsi, Y. M. Riyad, Z. H. Mohamed and H. M. Abd El Bary, "Decolorization of Mordant Red73 Azo Dye in Water Using $\mathrm{H}_{2} \mathrm{O}_{2} / \mathrm{UV}$ and Photo-Fenton Treatment," Journal of Hazardous Materials, Vol. 174, No. 1-3, 2010, pp. 352-358.

doi:10.1016/j.jhazmat.2009.09.057

[10] T. Robinson, G. McMullan, R. Marchant and P. Nigam, "Remediation of Dyes in Textile Effluent: A Critical Review on Current Treatment Technologies with a Proposed Alternative," Bioresource Technology, Vol. 77, No. 3, 2001, pp. 247-255. doi:10.1016/S0960-8524(00)00080-8

[11] S. J. T. Pollard, G. D. Fowler, C. J. Sollars and R. Perry, "Low-Cost Adsorbents for Waste and Waste-Water Treatment: A Review," Science of the Total Environment, Vol. 116, No. 1-2, 1992, pp. 31-52. doi:10.1016/0048-9697(92)90363-W

[12] V. K. Garg, M. Amita, R. Kumar and R. Gupta, "Basic Dye (Methylene Blue) Removal from Simulated Wastewater by Adsorption Using Indian Rosewood Sawdust: A 
Timber Industry Waste," Dyes and Pigments, Vol. 63, No. 3, 2004, pp. 243-250. doi:10.1016/i.dyepig.2004.03.005

[13] M. I. H. Farooqi and J. G. Srivastava, "The Toothbrush Tree (Salvadora Persica)," Quarterly Journal of Crude Drug, Vol. 8, No. 3, 1968, pp. 1297-1299.

[14] E. Noumi, M. Snoussi, H. Hajlaoui, E. Valentin and A. Bakhrouf, "Antifungal Properties of Salvadora Persica and Juglans Regia L Extracts against Oral Candida Strains," European Journal of Clinical Microbiology \& Infectious Diseases, Vol. 29, No. 1, 2010, pp. 81-88. doi:10.1007/s10096-009-0824-3

[15] G. Annadurai, S. R. Juang and J. D. Lee, "Use of Cellulose-Based Wastes for Adsorption of Dyes from Aqueous Solutions," Journal of Hazardous Materials, Vol. 92, No. 3, 2002, pp. 263-274. doi:10.1016/S0304-3894(02)00017-1

[16] M. S. El-Geundi, "Color Removal from Textile Effluents by Adsorption Techniques," Water Research, Vol. 25, No. 3, 1991, pp. 271-273. doi:10.1016/0043-1354(91)90006-C

[17] M. Y. Miah, K. Volchek, W. Kuang and F. H. Tezel, "Kinetic and Equilibrium Studies of Cesium Adsorption on Ceiling Tiles from Aqueous Solutions," Journal of Hazardous Materials, Vol. 183, No. 1-3, 2010, pp. 712-717. doi:10.1016/j.jhazmat.2010.07.084

[18] G. Annadurai, M. Chellapandian and M. R. V. Krishnan, "Adsorption of Reactive Dye on Chitin," Environmental Monitoring and Assessment, Vol. 59, No. 1, 1999, pp. 111-119. doi:10.1023/A:1006072119624

[19] X. Zhao, K. Urano and S. Ogasawara, "Adsorption of Polyethylene Glycol from Aqueous Solution on MontmoRillonite Clays," Colloid and Polymer Science, Vol. 267, No. 10, 1989, pp. 899-906. doi:10.1007/BF01410338

[20] M. K. munir, Z. N yusuf, H. Abdul, Y. H. Fauzia and F. Rani, "Isotherm Studies for Determination of Removal Capacity of Bi-Metal (Ni And Cr) Ions by Aspergillus Niger," Pakistan Journal of Botany, Vol. 42, No. 1, 2008, pp. 593-604.

[21] N. T. Abdel-Ghani, R. M. El-Nashar and G. A. El-Chaghaby, "Removal of $\mathrm{Cr}$ (iii) and $\mathrm{Pb}$ (ii) from Solution by Adsorption onto Casuarina Glauca Tree Leaves," EJEAFChe, Vol. 7, No. 7, 2008, pp. 3126-3133.

[22] Y. S. Ho and G. McKay, "Pseudo-Second Order Model for Sorption Processes," Process Biochemistry, Vol. 34, No. 5, 1999, pp. 735-742. doi:10.1016/S0032-9592(98)00112-5

[23] B. H. Hameed, A. T. M. Din and A. L. Ahmad, "Adsorption of Methylene Blue onto Bamboo-Based Activated Carbon: Kinetics and Equilibrium Studies," Journal of Hazardous Materials, Vol. 141, No. 3, 2007, pp. 819825. doi:10.1016/j.jhazmat.2006.07.049

[24] W. J. Weber Jr. and J. C. Morris, "Kinetic of Adsorption on Carbon from Solution," Journal of the Sanitary Engineering Division, Vol. 89, No. 2, 1962, pp. 31-59.

[25] Y. S. Ho, W. T. Chiu and C. C. Wang, "Regression Analysis for the Sorption Isotherms of Basic Dyes on
Sugarcane Dust," Bioresource Technology, Vol. 96, No. 11, 2005, pp. 1285-1291. doi:10.1016/j.biortech.2004.10.021

[26] M. S. Aboul-Fetouh, T. M. Elmorsi, J. M. El-Kady and H. A. El-Adawi, "Water Hyacinth Stems a Potential Natural Adsorbent for the Adsorption of Acid Green 20 Dye," Environmental Science: An Indian Journal, Vol. 5, No. 4, 2010, pp. 257-266.

[27] S. Senthilkumaar, P. R. Varadarajan, K. Porkodi and C. V. Subbhuraam, "Adsorption of Methylene Blue onto Jute Fiber Carbon: Kinetics and Equilibrium Studies," Journal of Colloid and Interface Science, Vol. 284, No. 1, 2005, pp. 78-82. doi:10.1016/j.jcis.2004.09.027

[28] D. Kavak, "Removal of Boron from Aqueous Solutions by Batch Adsorption on Calcined Alunite Using Experimental Design," Journal of Hazardous Materials, Vol. 163, No. 1, 2009, pp. 308- 314. doi:10.1016/j.jhazmat.2008.06.093

[29] B. H. Hameed, "Grass Waste: A Novel Sorbent for the Removal of Basic Dye from Aqueous Solution," Journal of Hazardous Materials, Vol. 166, No. 1, 2009, pp. 233 -238. doi:10.1016/j.jhazmat.2008.11.019

[30] A. A. Jalil, S. Triwahyono, S. H. Adam, N. D. Rahim, M. A. Aziz, N. H. Hairom, N. A. Razali, M. A. Abidin and M. K. Mohamadiah, "Adsorption of Methyl Orange from Aqueous Solution onto Calcined Lapindo Volcanic Mud," Journal of Hazardous Materials, Vol. 181, No. 1-3, 2010, pp. 755-762. doi:10.1016/j.jhazmat.2010.05.078

[31] M. Dogan and M. Alkan, "Removal of Methyl Violet from Aqueous Solution by Perlite," Journal of Colloid and Interface Science, Vol. 267, No. 1, 2003, pp. 32-41. doi:10.1016/S0021-9797(03)00579-4

[32] V. C. Srivastava, I. D. Mall and I. M. Mishra, "Characterization of Mesoporous Rice Husk Ash (RHA) and Adsorption Kinetics of Metal Ions from Aqueous Solution onto RHA," Journal of Hazardous Materials, Vol. 134, No. 1-3, 2006, pp. 257-267. doi:10.1016/j.jhazmat.2005.11.052

[33] R. L. Uma, V. C. Srivastava, I. D. Mall and D. H. Lataye, "Rice Husk Ash as an Effective Adsorbent: Evaluation of Adsorptive Characteristics for Indigo Carmine Dye," Journal of Environmental Management, Vol. 90, No. 2, 2009, pp. 710-720. doi:10.1016/j.jenvman.2008.01.002

[34] W. T. Tsai, C. Y. Chang, M. C. Lin, S. F. Chien, H. F. Sun and M. F. Hsieh, "Adsorption of Acid Dye onto Activated Carbons Prepared from Agricultural Waste Bagasse by $\mathrm{ZnCl}_{2}$ Activation," Chemosphere, Vol. 45, No. 1, 2001, pp. 51-58. doi:10.1016/S0045-6535(01)00016-9

[35] P. K. Malik, "Dye Removal from wastewater Using Activated Carbon Developed from Sawdust: Adsorption Equilibrium and Kinetics," Journal of Hazardous Materials, Vol. 113, No. 1-3, 2004, pp. 81-88. doi:10.1016/j.jhazmat.2004.05.022

[36] C. Namasivayam and D. Kavitha, "Removal of Congo Red from Water by Adsorption onto Activated Carbon 
Prepared from Coir Pith, an Agricultural Solid Waste," Dyes and Pigments, Vol. 54, No. 1, 2002, pp. 47-58. doi:10.1016/S0143-7208(02)00025-6

[37] I. A. W. Tan, A. L. Ahmad and B. H. Hameed, "Adsorption of Basic Dye Using Activated Carbon Prepared from Oil Palm Shell: Batch and Fixed Bed Studies," Desalination, Vol. 225, No. 1-3, 2008, pp. 13-28. $\underline{\text { doi:10.1016/j.desal.2007.07.005 }}$

[38] C. Saniz-Diaz and A. Griffiths, "Activated Carbon from Solid Wastes Using a Pilot Scale Batch Flaming Pyrolyser," Fuel, Vol. 79, No. 15, 2000, pp. 1863-1871. doi:10.1016/S0016-2361(00)00052-1

[39] C. H. Weng, Y. T. Lin and T. W. Tzeng, "Removal of Methylene Blue from Aqueous Solution by Adsorption onto Pineapple Leaf Powder," Journal of Hazardous Ma- terials, Vol. 170, No. 1, 2009, pp. 417-424.

doi:10.1016/i.jhazmat.2009.04.080

[40] S. J. Allen, G. Mckay and K. Y. H. Khader, "Intraparticle Diffusion of a Basic Dye during Adsorption onto Sphagnum Peat," Environmental Pollution, Vol. 56, No. 1, 1989, pp. 39-50. doi:10.1016/0269-7491(89)90120-6

[41] D. N. Jadhav and A. K. Vanjara, “Adsorption Kinetics Study: Removal of Dyestuff Effluent Using Sawdust, Polymerized Sawdust and Sawdust Carbon-II." Indian Journal of Chemical Technology, Vol. 11, No. 1, 2004, pp. 42-50.

[42] M. Prasad and S. Saxena, "Sorption Mechanism of Some Divalent Metal Ions onto Low-Cost Mineral Adsorbent," Industrial \& Engineering Chemistry Research, Vol. 43, No. 6, 2004, pp. 1512-1522. doi:10.1021/ie030152d 